\section{Letter from the President}

by Tae Hong Park

September 1, 2011

Dear ICMA Members,

It was wonderful seeing many of you at the 2011 ICMC hosted by Huddersfield University. For those members who were not at the conference this year, I am happy to report that the conference chair, Michael Clarke, and his team did a fantastic job in organizing and running the conference, thus providing the delegates with an intense yet relaxing and very enjoyable conference experience. It was indeed a very successful conference, and I am certain that it will be a memorable one for many years to come. Looking towards next year, the 2012 ICMC will be chaired by Miha Ciglar and will be held in Ljubljana, the capital and largest city in Slovenia. It is the first time in the long history of ICMA that the conference's annually changing "home" will be in this region. I hope to see many of our current and new members, as Miha Ciglar is planning numerous exciting events within the basic framework of the structure of ICMC conferences.
We are also happy to announce that the 2013 ICMC will be hosted in Perth, Australia. The conference, which will be co-chaired by Cat Hope and Lindsay Vickery, is yet another first for the ICMC record books, as it will mark the first time that our conference will be held in Australia.

To help our conference organizers, we are currently in the midst of creating a permanent conference submission site for future ICMCs and are planning to have it on-line in time for 2012 and subsequent ICMCs. This service will be provided free to our future ICMC hosts. We are, however, also investigating possibilities of offering it to other organizers as a service to our computer music community. In lieu of the submission site, we are also set on building a computer music archive that will be based on "music" submissions to the ICMC conferences. This will entail storing of audio files, program notes, technical details, various metadata, and other important information fields to preserve, archive, and provide a hub for research, study, and exploration of our music to the general public.

Other ICMA updates for this year include an increase in the number of \$100 ICMC student scholarships form 40 to 50; the addition of a new policy whereby senior ICMA members can now receive senior discounts towards ICMC registration 
fees; and giving away banquet ticket prizes at the membership meeting for the 2012 ICMC. These are just some of the activities ICMA has been engaged in, and we hope to have more exciting news for you soon.

We are always interested in hearing from potential ICMC conference hosts. If you would like information, have any questions regarding what hosting an ICMC is all about, or are considering organizing an ICMC conference please do not hesitate to contact the VP for Conferences Meg Schedel and me (the most up-to-date email addresses can be found on the ICMA website).

If you have any other questions, suggestions, comments, or concerns regarding the ICMA or the ICMC, please do not hesitate to contact me or the appropriate ICMA directors or officers. We hope to see y'all at the 2012 ICMC in Ljubljana!

Tae Hong Park

Associate Professor

Georgia State University School of Music

\section{Letter from the Editor}

It is my pleasure to bring you the 2010-11 issue of Array. Some of the content in this issue has already appeared on our blog, which has been up and running since last November at http:/ / arrayblog.wordpress. com. It is our hope that the blog will continue to allow for a more frequent release of content with an opportunity for member feedback. If you have not already done so, please point your RSS readers to the blog and be notified when new articles are posted.

If you would be willing to write something for Array, have feedback about this issue, ideas for future issues or blog posts, or have materials you would like reviewed, please send email to array@,computermusic.org. Lists of items that are available for review will be posted on the Array blog periodically. Those interested in writing a review should also include a mailing address and any particular items or areas of interest, so that we can send you the appropriate materials. CD/DVD and book reviewers will be able to keep review copies free of charge. Please consider contributing; the success of Array depends on input from its readers.

This issue will be my last as editor. A new editor will be announced soon. I have enjoyed working on Array since 2007, and I 